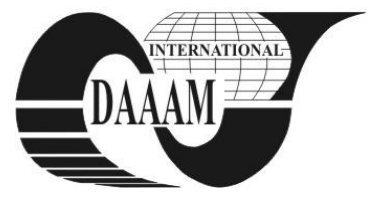

Annals of DAAAM for 2011 \& Proceedings of the 22nd International DAAAM Symposium, Volume 22, No. 1, ISSN 1726-9679 ISBN 978-3-901509-83-4, Editor B. Katalinic, Published by DAAAM International, Vienna, Austria, EU, 2011 Make Harmony between Technology and Nature, and Your Mind will Fly Free as a Bird

Annals \& Proceedings of DAAAM International 2011

\title{
A MATHEMATICAL STUDY REGARDING FORCES EFFECTS DURING ORTHODONTIC TREATMENT
}

\section{SZUHANEK, C[amelia] A[lexandrina]; CERNESCU, A[nghel]; FAUR, N[icolae]; JIANU, R[odica] D[oina]; FLESER, T[raian] \& MUNTEAN, E[lena] A[driana]}

\begin{abstract}
The purpose of ours study was to evaluate the effect of forces applied to the tooth during orthodontic treatment. The experiment took place at the Department of Strenght of Materials, Politechnica University of Timisoara, Romania. The geometrical models were obtained after $3 D$ scans of natural teeth and the use of Solidworks 2007 software. The geometrical models were imported in a FEA software,ABAQUS $v$ 6.9.3. Their were subjected to forces similar to those used during orthodontic treatment, with the intensity of $1 \mathrm{~N}$. The distance between the force application point and bone insertion highly influenced the concentrations of stress and the values of total initial displacements.
\end{abstract}

Key words: biomechanics, mathematical models, finite elements analysis, orthodontics

\section{INTRODUCTION}

Understanding how teeth move in response to mechanical loads is an important aspect of orthodontic treatment. The finite elements analysis can be used in the evaluation of different stages of orthodontic treatment, as recommended by previous studies. Treatment planning should include consideration of the appliances that will meet the desired loading of the teeth to result in optimized treatment outcomes.

Previous studies have shown that treating periodontal patients with lingual appliances requires specific considerations in the biomechanical approach. In case of periodontal disease and of alveolar bone loss, the center of resistance will be modified, and the application point of orthodontic forces will vary. Among the advantages in lingual biomechanics is the closer distance between the point of force application and the center of resistance.

The purpose of our work was to evaluate, by mathematical methods, the response of dento-alveolar reactions to orthodontic forces, depending on the force application point and bone insertion. This study has continued the research published by authors in their previous articles(Szuhanek, Cernescu and colab. 2006, 2009, 2010) and it is a part of a more complex research project.

\section{MATERIALS AND METHODS}

The experiment took place at the Department of Strenght of Materials, Politechnica University of Timisoara, Romania. The geometrical models were obtained after 3D scans of natural teeth and the use of Solidworks 2007 software. A laser Picza scanner was used on in order to obtain realistical models of the teeth taken into this study. The geometrical models were then imported in a FEA software,ABAQUS v 6.9.3. The material parameters were those recommended by Andersen and colab. In their study from 1991.
The 3 models were constructed as follows:

A - the distance between the application point of force and bone insertion is $5 \mathrm{~mm}$.

$\mathrm{B}$ - the distance between the application point of force and bone insertion is $6 \mathrm{~mm}$.

$\mathrm{C}$ - the distance between the application point of force and bone insertion is $7 \mathrm{~mm}$..

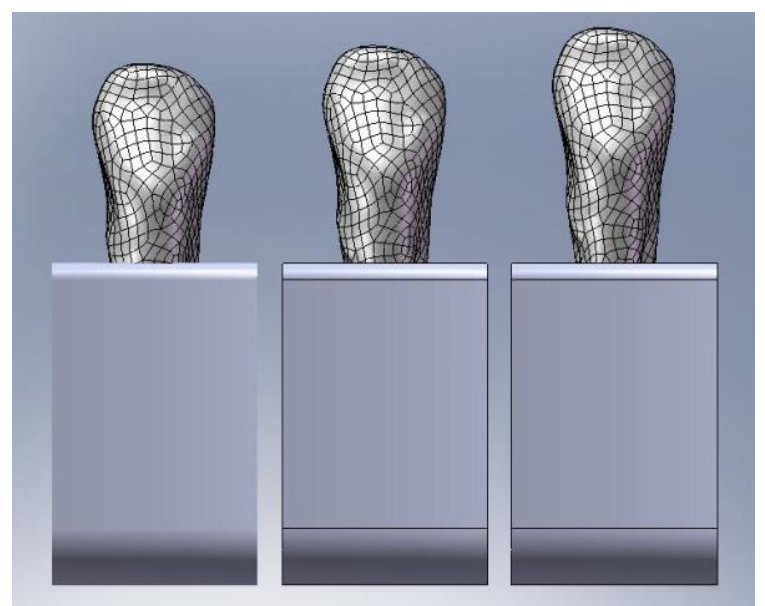

Fig.1. Geometrical models taken into this study ( A, B,C)

The models were subjected to forces similar to those used during orthodontic treatment, with the intensity of $1 \mathrm{~N}$. The size of the elements used in this models was similar in all three cases. The calculated parameters were the initial displacements in the three directions $(\mathrm{oX}, \mathrm{oY}, \mathrm{oZ})$, the total initial displacements and the Von Mises tension(equivalent of stress). The importance of initial displacements is related to the desired orthodontic movement and in preventing unwanted rotational effects. The Von Mises tension is an indicator of stress distribution and concentration during orthodontic movements. Higher values can have negative effects of periodontal and alveolar bone structures.
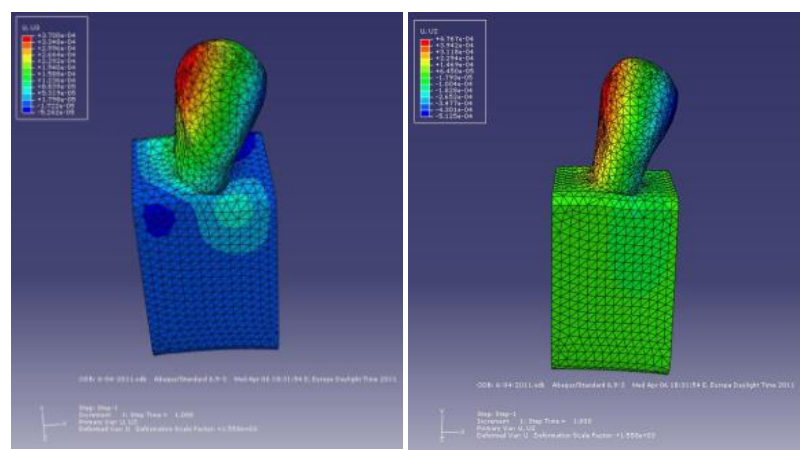

Fig.2.a Initial displacements distribution in the oX and oY directions 


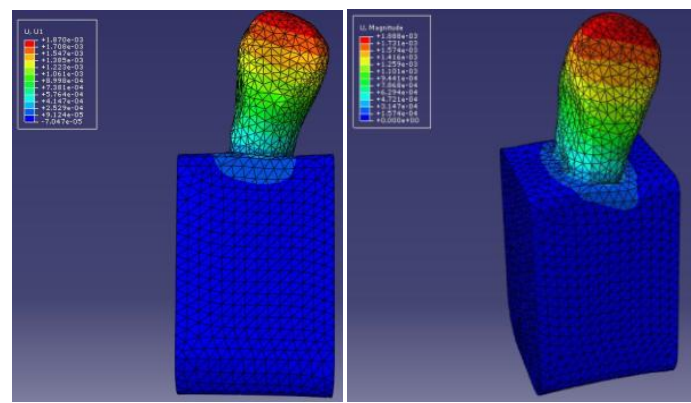

Fig.2.b Initial displacements distribution in the $\mathrm{oZ}$ direction for model C. Total initial displacements
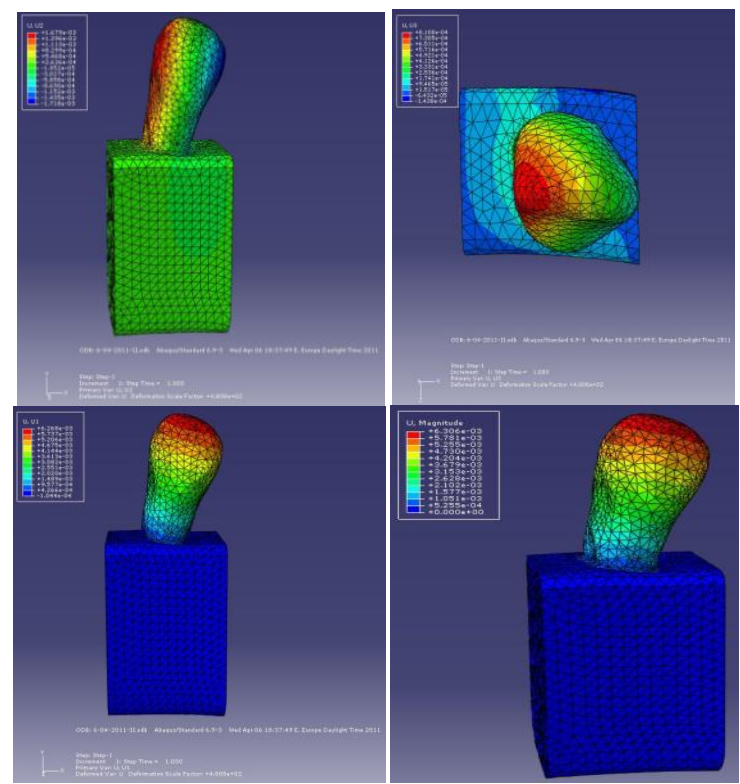

Fig. 3. Initial displacements distribution in the 3 directions for model B. Total initial displacements

The values of initial displacements was lower in the A model, than the other studied models $(\mathrm{B}, \mathrm{C})$. This is important in clinical activities, since the rate of tooth movement highly depends on the force applied. The higher values of initial displacements in oX direction were a result of the type of force application(tipping).

The distribution and values of on Mises stress were different in the models taken into this study. The highest concentrations of stress were noted in the cervical aproximal areas, in the PDL and the surrounding alveolar bone.

The distance between the force application point and bone insertion highly influenced the concentrations of stress and the values of total initial displacements. The accuracy of force application is also very important in obtaining clinical success. Positioning of the brackets in lingual orthodontics requires specific attention, a small mistake can result in unnecessary stress concentrations and unwanted movements.

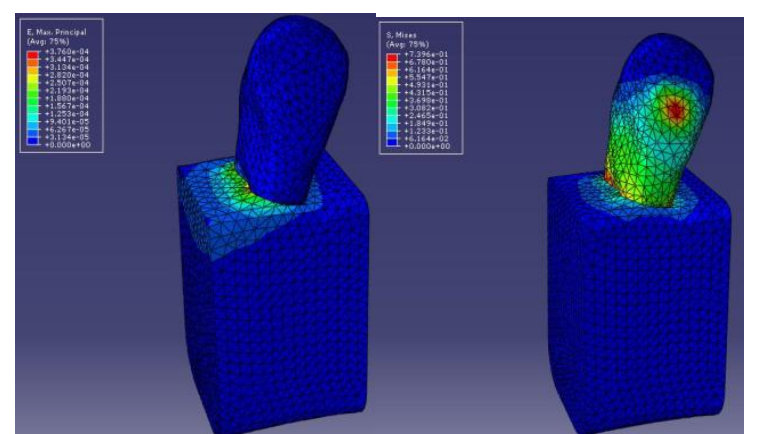

Fig. 4. The variation of Von Mises tension after the application of force

\section{CONCLUSIONS}

Our study has shown that the biomechanical parameters of orthodontic movement such as stress and initial displacements are highly dependent of the amount of bone loss and of the force application point.

Future work is required in order to evaluate the complex reactions of dento-alveolar tissues in all types and stages of orthodontic treatment.

\section{ACKNOWLEDGMENT}

This work was supported by CNCSIS -UEFISCSU, project number PNII - IDEI code 1738/2008.

\section{REFERENCES}

Andersen KL, Pedersen EH, Melsen B., Material parameters and stress profiles within the periodontal ligament. Am J Orthod Dentofacial Orthop. 1991 May; 99(5): 427-40

C.Szuhanek, Faur N., Cernescu A.: Biomechanical 3D analysis of stress induced by orthodontic implants. Key Engineering Materials, vol.399(2009), pp 194-204

Faur, N. Finite elements: fundaments. [Elemente finite: fundamente] Ed.Politehnica, Timişoara,2002

Nicolae Ghiban, Cristina Maria Bortun, Ilare Bordeasu, Brândusa Ghiban, Nicolae Faur, Anghel Cernescu, Stela Carmen Hanganu: Evaluation of Mechanical Properties by Stereo-and Scanning Electron Microscopy of Some Heat Curing Dental Resins, MATERIALE PLASTICE 47, Nr. 2, 2010, pp. 240-243, ISSN 0025/5289 FI(0)

Nicolae Faur, Cristina Bortun, Liviu Marşavina, Anghel Cernescu, Otilia Gombos: Durability studies for complete dentures, Proceedings of the 8th International Conference on Fracture and Damage Mechanics, FDM, 8-10 september 2009, Malta, Ed. Ttp TRANS TECH PUBLICATIONS LTD Switzerland UK USA, ISBN 0-87849-315-8, ISBN 13978-0-87849-315-9, Key Engineering Materials. Vol. 417-418(2010), pp. 725-728, http://www. scientific.net

Szuhanek, C., Cernescu A., Faur N., Fleser T., Vatau S., CHEVERESAN A. Numerical simulation of orthodontic forces effects in bone loss cases. Annals of DAAAM for 2010 \& Proceedings of 21th DAAAM International Symposium. Zadar, Croatia, octomber 2010

Szuhanek C., Cernescu A., Faur N., Glavan F., Fleser T., Vatau S. - Finite element simulation of first molar movement during orthodontic treatment. Annals of DAAAM for 2009 Proceedings vol.20 no.1 pag.953-954. ISBN 978 - 3901509-70-5

Szuhanek C.: Periodontal implications in orthodontics. PhD thesis. (Implicatii parodontale in anomaliile dento-maxilare. Teza de doctorat). Timisoara, Romania, 2006.

Szuhanek C. Finite elements analysis of lingual forces effects in alveolar bone loss cases. www.lingualnews.com Vol 5 No 1 May 2007 